\title{
A Qualitative Study of Patient Perspectives of Their Infertility Treatment Journey from Diagnosis to Seeking Ayurvedic Treatment
}

\author{
Sapre S. \\ Neville Wadia Institute of Management Studies and Research, Pune \\ sapresneha4@gmail.com
}

\begin{abstract}
Infertility among married couples is on rise and the need for infertility treatment is increasing. There are various infertility treatments available that can be categorised based on the medical systems into Allopathic treatments and non-Allopathic treatments including Ayurveda, Homeopathy etc. All these types of infertility treatments offer remedies based on the nature of diagnosed infertility and cause of the problem. Ayurveda is one of the oldest non-allopathic medical systems practised in India.

This study is aimed at understanding the patient types in Pune and the different pathways that they take while opting Ayurvedic treatmentfor infertility.This paper will also give insights about the psychological and non-psychological factors infertility patients are associated with while undergoing diagnosis and treatment
\end{abstract}

Keywords

Article Received: 10 August 2020, Revised: 25 October 2020, Accepted: 18 November 2020

\section{Introduction}

Medical definition of Infertilitystates that it is the incapability to conceive after one year of regular sexual intercourse without contraceptive measures undertaken or after six months if the woman is over age 35 . The definition also includes women with inability to carry their pregnancy to live birth. The two general types of infertility described in World Health Organization (WHO) include primary and secondary infertility. According to WHO definition, when a woman is unable to ever bear a child, either due to the inability to become pregnant or the inability to carry a pregnancy to a live birth she would be classified as patient with primary infertility. This means, women who miscarries her pregnancy spontaneously, or when her pregnancy results in a still born child, without ever having had a live birth would be a patient with primary infertility. When a woman is unable to bear a child, either because she is unable to become pregnant or if she is unable to carry a pregnancy to a live birth followed by either a previous pregnancy or by a previous ability to carry a pregnancy resulting into a live birth, she would be classified as patient having secondary infertility. Thus those women who repeatedly miscarryspontaneously or whose pregnancy results into a stillbirth, or following a previous pregnancy or a previous ability to do so, are then not capable to carry a pregnancy to a live birth would be patients with secondary infertility.

International Business Times (IBT) article has quoted that it is believed that $10 \%$ of the general population suffers from some form of infertility in India. Considering the current Indian population of 1.35 billion, the estimation of the number of Indians suffering from infertility can be 0.14 billion which is huge.

According to the researches published by Verdurmen et al., (1995) and van Balen et al., (1997), seeking medical advice is the most commonly chosen alternative among infertile couples over other alternatives such as adoption, fostering etc.
Infertility treatment optionsunder Allopathy are offered to couples depending on the cause of the problem and the nature of diagnosis of infertility. A significant majority of female patients are successfully treated with the administration of certain infertility treatment drugs such as Clomiphene Citrate, Bromocriptine or Gonadotrophins. If the patient is diagnosed with damage to the reproductive organs, surgery is recommended by physicians to resolve the problems, for instance those caused by endometriosis and infectious diseases. The treatment options available for infertility in male patients include the administration of certain drugs, surgery and assisted reproductive technologies (ART), such as Intracytoplasmic Sperm Injection (ICSI) in which a single sperm injection is inserted into the ovum using minute needle to create pregnancy.Assisted reproductive technologies (ART) are a part of several different methods designed to overcome barriers that create problems for natural fertilization. Few examples of such barriers include anatomical problems of blocked fallopian tubes. One of the most common techniques is in-vitro fertilization (IVF) now been practiced for more than 15 years.

Non-allopathic Indian medicines, that are referred to elsewhere in the world as complementary and alternative medicines, have gathered rising recognition in recent years with regard to both treatment options and health hazards. Non-allopathic systems such as Ayurveda, Siddha, Unani and Homeopathy are practiced in India. These systems comprise a variety of therapeutic approaches that include diet, herbs, metals, minerals, precious stones and their combinations as well as nondrug therapies.

Individuals or couples all around the world experience a stressful situation due to their inability to conceive children. There are manifold consequences of infertility including societal repercussions and personal suffering. With advances in assisted reproductive technologies, such as IVF, offering hope to many couples where treatment is available, there are 
barriers in terms of medical coverage and affordability that exist and add to the stresses. During their medicalization of infertility, couples experience lot of emotional responses, which include distress, loss of control, stigmatization, and a disruption in the developmental trajectory of adulthood. Fertility treatment is predominantly delivered to the patients and is of varying quality and focuses primarily, if not solely, on resolving causes of infertility; often with little regard for the wider impact that infertility poses. There is emerging evidence of an association between stress of fertility treatment and patient drop-out and pregnancy rates. Many psychological interventions, especially those emphasizing stress management, counselling and coping-skills training, have been researched to show the beneficial effects for infertility patients.

This qualitative study explores the perspectives of adults with infertility and aims to develop a patient journey template based on journeys of infertility patients from diagnosis to seeking Ayurvedic treatment.The term 'patient journey' can be referred to the experiences and steps in the pathway the patient undertakes during the course of disease diagnosis and its medical treatment.

\section{Objectives of the study-}

1. To study different factors associated with Infertility treatment

2. To understand the various steps in Infertility patient journey from diagnosis to seeking Ayurveda

\section{Research Methodology -}

An exploratory research design was employed to collect data via face to face unstructured interviews. These interviews allowed participants to fully articulate their experiences and provided an excellent opportunity to understand their concerns. A sample size of 12 consenting participants seeking Ayurvedic infertility treatment was considered for data collection during February - May 2019. The inclusion criteria for respondents was medically diagnosed fertility or reproductive problems for over 6 months and able to provide informed consent.

\section{Findings}

\section{Patient journey of an individual from infertility diagnosis to seeking Ayurvedic treatment-}

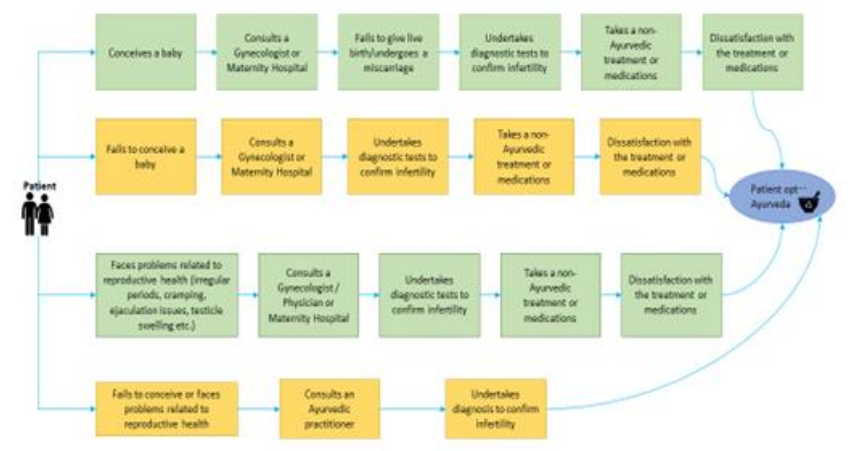

Figure 1: Patient journey of Infertility patients from diagnosis to seeking Ayurveda

On the basis of patient cases treated for infertility, studied during the research, four journey patterns classified by types of infertilities were identified.

- Pathway 1 - This pathway is of the patients who generally conceive and start initial medical counselling in a Maternity hospital or with a Gynaecologist but fail to give live birth due to medical conditions such as blighted ovum, uterine problems, genetic aberrations etc. These patients are advised to undertake complete clinical diagnosis to understand the root cause of infertility. Since the basic medical treatment and diagnosis is initiated at the Maternity hospitals which are predominantly Allopathy based, further medical treatment for infertility suggested to the patient is Allopathic. If the patient is not satisfied with Allopathic treatment, only then this patient seeks non-Allopathic infertility treatmentsuch as Ayurveda. According to the patients, the reasons of their dissatisfaction with Allopathic treatment were dissatisfaction with hormone based drug treatments, desire to cure illness naturally, no desired outcome from the therapy etc.

- $\quad$ Pathway 2 - This pathway starts with patients that are unable to conceive a baby and generally visit a Gynaecologist or Maternity hospital to seek advice. They are clinically tested to identify and confirm infertility problem. Since the initial prognosis and medical tests are conducted at an Allopathic clinic or Maternity hospitals, these patients undertake Allopathic fertility treatments initially. If these patients are not satisfied with the initial medical treatment, they switch to non-Allopathic treatment such as Ayurveda.

- $\quad$ Pathway 3 - Among the patients interviewed, some had been facing issues related to reproductive health. Some of the issues mentioned were irregular periods, excessive menstrual cramping, etc. in females, and ejaculation issues, testicle swelling etc. in males. These patients consult physician and undertake clinical diagnosis. If these patients are identified to be at risk of infertility, they are suggested medical treatment. In case of dissatisfaction with the medical treatments of Allopathy, Homeopathy or any other suggested non-Ayurvedic treatment, these patients seek Ayurveda for fertility counselling and treatment.

- Pathway 4 - The patients who have opted Ayurveda for other ailments or have been taking Ayurvedic treatments for any illness seek Ayurvedic practitioner in case they fail to conceive or face issues with reproductive health. They undergo medical diagnosis and get initiated on Ayurvedic treatment to solve their infertility problems.

\section{Psychological or emotional factors-}

This articlehas exploredvarious psychological-emotional problem parametersor factors with devastating effects on the mental health and well-being of the infertile individuals and couples. The infertility is often treated as a medical issue with less attention on the mental-emotional, social and cultural aspects.

The findings of this study include four dimensions of psychological factors associated with infertility patients: 
- $\quad$ Cognitive response to infertility diagnosis: This includes psychological turmoil, difficulty in acceptance, stress of informing family members etc.

- Cognitive response to infertility treatment: This includes psychological turmoil, reduced self-esteem, low confidence etc.

- $\quad$ Emotional response to infertility diagnosis: This includes feelings of failure, grief, fear, anxiety, worry about family and societal image, depression, regret etc.

- $\quad$ Emotional response to infertility treatment: This includes fear, anxiety and worry; fatigue and helplessness; grief and depression; hopelessness; distrust on treating physician or therapy process etc.

\section{Non-psychological factors-}

Based upon the respondent experiences, this study determined several treatment system/facility related factors and Physician (giving treatment) related factors that directly or indirectly are associated with the Psychological factors among infertility patients.

- Treatment system/facility related factors: These include provision of information, competence of clinic and staff, treatment facility accessibility, transition and physical comfort, check-up and diagnostic facilities including equipment, etc.

- $\quad$ Physician related factors: These include attitude of physician, relationship or trust on physician, counselling pattern, communication, patient involvement,privacy and emotional support, etc.

\section{Conclusion}

This study revealed four main pathways infertility patients undertake when they seek Ayurvedic fertility treatments based on the type of infertility patient case. This study identified four main psychological factors associated with these infertility patients categorised into Cognitive responses to diagnosis and treatment and Emotional responses to diagnosis and treatment.

\section{References}

[1] Van Balen F, Verdurmen J. Medical anxiety and the choice for treatment: the development of an instrument to measure fear of treatment. Psychol Health 1999;14:927-935.

[2] Van Balen F, Verdurmen J, Ketting E. Choices and motivations of infertile couples. Patient EducCouns1997;31:1927.

[3] Verdurmen J, Van Balen F, Ketting E. Infertility: patient behaviour and decision making. PsychosomObstetGynecol (11th International Congree of psychosomatic Obstetrics and Gynaecology), 295-300.
[4] Domar, A. D., \& Seibel, M. M. (1990). Emotional aspects of infertility. In M. M. Seibel (Ed.), Infertility: A comprehensive text(pp. 23-35). East Norwalk, CT, US: Appleton \& Lange.

[5] Dancet EAF, van Empel IWH, Rober P, Nelen WLDM, Kremer JAM, D'Hooghe T. Patient-centred infertility care: a qualitative study to listen to the patient's voice, Hum Reprod , 2011, vol. 26 (pg. 827-833)https://doi.org/10.1111/14679876.00082

[6] Hasanpoor-Azghdy SB, Simbar M, Vedadhir A. The emotional-psychological consequences of infertility among infertile women seeking treatment: Results of a qualitative study. Iran $\mathbf{J}$ Reprod Med. 2014;12(2):131-138.

[7] S. Gameiro, J. Boivin, L. Peronace, C.M. Verhaak, Why do patients discontinue fertility treatment? A systematic review of reasons and predictors of discontinuation in fertility treatment, Human Reproduction Update, Volume 18, Issue 6, November/December 2012, Pages 652669, https://doi.org/10.1093/humupd/dms031

[8] VerhagenTEM, Dumoulin JCM, Evers JLH, Land JA. What is the most accurate estimate of pregnancy rates in IVF dropouts?, Hum Reprod , 2008, vol. 23 (pg. 1793-1799)International Business Times https://www.ibtimes.co.in/infertility-rateamong-indian-couples-on-the-rise-sayssurvey-507672\#

[9] World Health Organization on Infertilityhttp://www.who.int/reproductivehealth/top ics/infertility/definitions/en/ 